\title{
OS 'OLHARES’ DA COMUNICAÇÃO NOS ESTÁGIOS DA INSTITUCIONALIZAÇÃO: UM ESTUDO DE CASO EM UMA AGÊNCIA DE INOVAÇÃO
}

\section{THE ' GLANCES ' OF COMMUNICATION IN THE STAGES OF INSTITUTIONALIZATION: A CASE STUDY IN AN INNOVATION AGENCY}

\author{
Renato Fabiano Cintra \\ Universidade Estadual de Londrina \\ Londrina, PR, Brasil \\ E-mail: renatocintra@hotmail.com \\ Letícia Fernandes de Negreiros \\ Universidade Estadual de Londrina \\ Londrina, PR, Brasil \\ E-mail: leticia_negreiros@hotmail.com \\ Marlene Regina Marchiori \\ Universidade Estadual de Londrina \\ Londrina, PR, Brasil \\ E-mail: marlenemarchiori@gmail.com
}

Saulo Fabiano Amâncio-Vieira

Universidade Estadual de Londrina

Londrina, PR, Brasil

E-mail: saulo@uel.br

\section{RESUMO}

O presente estudo busca compreender quais relações entre comunicação e organização podem emergir nos estágios da institucionalização da Agência de Inovação Tecnológica (Aintec) da Universidade Estadual de Londrina. Quanto aos procedimentos metodológicos, esta pesquisa se caracteriza como qualitativa, exploratória, descritiva, apresentando como estudo de caso o processo de institucionalização da Aintec/Uel. Evidencia-se na pesquisa a relação da contenção, como a mais frequente do ponto de vista da visibilidade prática, não sendo possível captar as relações de produção e equivalência, em função do processo de estruturação da Agência ter ficado quase que exclusivamente na responsabilidade de um único gestor.

Palavras-chave: Comunicação. Organização. Institucionalização. Comunicação e Institucionalização.

\begin{abstract}
This study seeks to understand which relationships between communication and organization can emerge in the early stages of the institutionalization of the Technology Innovation Agency (Aintec) of State University of Londrina. Regarding methodological procedures, this research is characterized as qualitative, exploratory, descriptive, presented as a case study the process of institutionalization of Aintec / Uel. It is evident from the study that the containment's relations such as more frequent visibility point of view of practice, and it isn't possible to capture the relations of production and equivalence, due to the structuring process of the Agency have been almost exclusively in the responsibility a single manager.
\end{abstract}

Keywords: Communication, Organization, Institutionalization, Communication and Institutionalization.

Data de submissão: 17 de outubro de 2013.

Data de aprovação: 22 de agosto de 2018. 


\section{INTRODUÇÃO}

O desenvolvimento da Teoria das Organizações (TO) tem sido influenciado por mudanças sociais, políticas, econômicas e tecnológicas na sociedade como um todo. Em tempos recentes os estudos organizacionais experimentam um vigoroso impulso no Brasil, tendo acumulado razoável produção científica (CALDAS; FACHIN, 2007). Assim, percebe-se como a Teoria Institucional (TI) é distinta para explicar a estrutura organizacional (TOLBERT; ZUCKER, 1999). De tal modo, esta teoria incorpora a ideia de instituições, padrões de comportamento, normas e valores, crenças e pressupostos, nos quais se encontram imersos em organizações, grupos e indivíduos (MACHADO-DA-SILVA; GONÇALVES, 1999).

Apesar desses avanços, a TI não é suficiente para explicar sozinha a complexidade organizacional. Para tanto, vislumbra-se na Teoria da Comunicação uma aliada para uma melhor compreensão das questões organizacionais. Além disso, Papa, Daniels e Spiker (2008) apud Caldas (2010, p. 29) enfatizam que "a ideia de comunicação e organização como elementos conexos da realidade organizacional sempre esteve presente, explícita ou implicitamente, na história de Estudos Organizacionais", ou seja, comunicação e organização são complementares e não dicotômicas.

Além disso, a comunicação na organização não deve ser vista de maneira simplista, mas sim como processo e dimensão estruturante da própria organização, que Caldas (2010), torna a visão mais completa. Para tal, faz-se necessária ampliar o 'olhar' da comunicação para além das mensagens (visão estreita do processo comunicacional), evidenciando a dimensão da comunicação como processo (MARCHIORI, 2010), ou seja, não há inicio, meio e fim, já que deve ser compreendida como um movimento contínuo. Desta forma, observam-se pessoas criando sentido para suas ações nos processos de construção social da realidade (BERGER; LUCKMANN, 2011) e sua manutenção.

Seguindo também as proposições de Lammers e Barbour (2006), verifica-se que a comunicação alinha as organizações com instituições, ao passo em que as instituições também são constituídas comunicativamente, e que o sucesso da comunicação entre a organização e seu ambiente depende da presença de instituições. Portanto, "as organizações podem e devem ser vistas como fenômenos da comunicação" (MARCHIORI, 2008, p. 81).

Vale ressaltar ainda, e recorrendo a Lammers e Barbour (2006), que a pesquisa em comunicação organizacional, a partir de várias críticas, tem concentrado no microfenômeno (ação individual), negligenciando o macro (estrutura social), muitas vezes por indeterminação conceitual e abrangência do que é tido como macro nesse campo. Deste modo, uma teoria institucional da comunicação organizacional, bem como um olhar da comunicação neste macro fenômeno preenche essa lacuna e permite ainda, entendimento de forma a transcender as organizações e situações particulares (LAMMERS; BARBOUR, 2006).

Nesse sentido, este estudo busca compreender as relações da comunicação com a organização proposta por Smith (1993), nos estágios da institucionalização evidenciados por Tolbert e Zucker (1999). No intuito de nortear o presente artigo, a problemática central versa sobre: Quais relações da comunicaçãoorganização emergem nos estágios da institucionalização?

Para tanto este artigo estrutura-se em cinco partes. Além da introdução, tem-se o suporte teórico alicerçado nos estágios da institucionalização e nas relações da comunicação e organização; na sequência apresenta-se os procedimentos metodológicos; na quarta parte busca-se descrever e relacionar os estágios 
da institucionalização e as relações comunicação e organização e para tanto, apresenta um estudo empírico que evidencie a discussão; e por fim, as considerações, com as principais contribuições do estudo e sugestões para novas pesquisas.

\section{REVISÃO TEÓRICA}

Nesta seção busca-se apresentar os 'olhares' da comunicação organizacional, caracterizando suas principais abordagens. Na sequência apresentam-se os estágios da institucionalização.

\section{Comunicação Organizacional e Seus 'Olhares'}

"Talvez nenhum outro conceito esteja tão presente no estudo das organizações quanto o designado pelo termo comunicação" (PUTNAM; PHILLIPS; CHAPMAN, 2004, p. 77). Assim, sabe-se que "na contemporaneidade a comunicação organizacional tem ocupado espaço relevante, seja no meio acadêmico ou no mundo corporativo" (KUNSCH, 2009, p. 63).

Com isso, vale ressaltar que muitos estudos, inclusive em comunicação, utilizam metáforas para ilustrar seus desencadeamentos e a busca da compreensão do fenômeno. Assim, as metáforas contribuem ao mostrar de maneira mais concreta visões e significados de como os indivíduos vêem o mundo (PUTNAM; PHILLIPS; CHAPMAN, 2004). No caso desse artigo, as metáforas de comunicação orientam o entendimento sobre a vida organizacional, mais especificamente sobre os 'olhares' da comunicação nos estágios do processo de institucionalização. Assim, são considerados, apresentados e discutidos três tipos de relacionamento entre organização e comunicação: contenção, produção e equivalência, conforme proposto por Smith (1993).

Na relação de contenção, que também é conhecida pela metáfora do contêiner, predomina a ideia de 'comunicação na organização', em que a organização serve como um contêiner à comunicação, ou seja, a comunicação é vista como contida na estrutura organizacional (SMITH, 1993), sendo apenas uma de suas variáveis (CASALI, 2004). Na metáfora do contêiner se tem "uma visão mecanicista e linear da comunicação, a qual pode ser medida e avaliada" (MARCHIORI, 2009, p. 6), ou conforme complementa Kunsch (2009, p. 72), nesta perspectiva "o comportamento comunicativo pode ser observável e tangível, medido e padronizado", o qual pode ser reificado (PUTNAM; PHILLIPS; CHAPMAN, 2004). Assim, a comunicação ficaria reduzida a simples transferência de informações, ou seja, "supõe-se que a comunicação reproduza as estruturas organizacionais e seja definida pelas necessidades organizacionais de ordem prática" (CASALI, 2009, p. 112).

Para Casali (2004) os outros dois tipos de relações propostos por Smith (1993) - produção e equivalência - estão inseridos na ideia de "comunicação como organização". Assim, fazem parte de uma noção em que a comunicação é vista como um processo organizante, no qual através do engajamento dos membros da organização há a construção dos diversos sistemas de significados (MUMBY, 2000 apud CASALI, 2004).

A segunda relação, de produção, pode ser vista de três maneiras. Na primeira forma a comunicação é tida como produtora da organização; já na segunda inverte-se esse papel, é a organização que produz 
comunicação, e na última possibilidade, a relação é de co-produção, em que ambas ficam variavelmente como produtor/produto (SMITH, 1993). Portanto, nessa relação discute-se "como as organizações produzem a comunicação, ou a comunicação produz a organização, ou ambas, reciprocamente, se co-produzem" (PUTNAM; PHILLIPS; CHAPMAN, 2004, p. 77; KUNSCH, 2009).

Esta metáfora parte do pressuposto que "não existe organização sem comunicação e não existe comunicação sem organização. Contudo, em uma relação de produção, surge o dilema da precedência de uma relação à outra ou do desenvolvimento concomitante" (CASALI, 2009, p. 112), ou seja, "qual das duas, a priori, surge primeiro: a comunicação ou a organização - ou ambas se desenvolvem concomitante?" (PUTNAM; PHILLIPS; CHAPMAN, 2004, p. 78). "Dessa forma, o que normalmente é designado como ação organizacional é uma ação individual legitimada por processos de comunicação. À medida que a comunicação se realiza, esta produz organização e a organização só se concretiza pela comunicação" (CASALI, 2009, p. 114).

Por fim, a terceira relação, a de equivalência, vai além ao vislumbrar que "comunicação é organização e organização é comunicação" (SMITH, 1993, p. 12), ou seja, comunicação e organização como uma só entidade ou um só fenômeno (TAYLOR, 1995 apud KUNSCH, 2009, p. 69) e que pode ser expresso de modos diferentes (PUTNAM; PHILLIPS; CHAPMAN, 2004), sendo impossível visualizar esses dois fenômenos separadamente. Esta relação postula uma mudança radical no relacionamento comunicação/organização (CASALI, 2009). Neste contexto, trata-se comunicação e organização como processos isomórficos (PUTNAM; PHILLIPS; CHAPMAN, 2004), remetendo ao pensamento de que "a comunicação é organização, assim como organização é comunicação" (CASALI, 2009, p. 112). Nessa relação a comunicação "é fonte e produto da organização, isto é coprodução dinâmica, ao mesmo tempo estrutura e processo" (TAYLOR; DELCAMBRE, 2011, p. 15). "As organizações não apenas se constituem pela comunicação, mas também se expressam em comunicação" (TAYLOR; COOREN, 1997 apud CASALI, 2009, p. 113).

Deste modo, no Quadro 1 uma síntese das principais ideias discorridas neste tópico.

Quadro 1. As Relações entre Comunicação e Organização

\begin{tabular}{|c|c|c|}
\hline $\begin{array}{l}\text { Relação } \\
\text { Comunicação e } \\
\text { Organização }\end{array}$ & Ideia Predominante & Elementos Principais \\
\hline Contenção & $\begin{array}{l}\text { 'Comunicação na } \\
\text { organização' }\end{array}$ & $\begin{array}{l}\text { - Comunicação como variável contida na organização } \\
\text { - Visão mecanicista e linear da comunicação } \\
\text { - Comunicação como simples transferência de informações }\end{array}$ \\
\hline Produção & $\begin{array}{l}\text { 'Comunicação como } \\
\text { organização' }\end{array}$ & $\begin{array}{l}\text { - } 3 \text { Relações: } \\
\text { Comunicação } \rightarrow \text { Organização } \\
\text { Comunicação } \leftarrow \text { Organização } \\
\text { Comunicação } \leftrightarrow \text { Organização }\end{array}$ \\
\hline Equivalência & & - Organização é comunicação \\
\hline
\end{tabular}

Fonte: Elaborado pelos autores, 2012.

Assim, parte-se do pressuposto de que "as noções de 'comunicação nas organizações' e 'comunicação como organização' não são dimensões excludentes; ao contrário, essas percepções parecem ser complementares" (CASALI, 2009, p. 122). Logo, remete a "um exercício conceitual para superar as dicotomias 
paradigmáticas, captando a dinâmica existente entre o mundo material e social, bem como entre as forças de ordem e mudança" (CASALI, 2009, p. 124). Além da discussão acerca das relações entre comunicação e organização, é imprescindível para o artigo a compreensão sobre os elementos fundamentais que contemplam os estágios da institucionalização organizacional, os quais são apresentados no tópico a seguir.

\section{A Teoria Institucional e os Estágios da Institucionalização Organizacional}

É a partir de 1940, que os estudos organizacionais antes focados na linha racional, em que o indivíduo era visto como coadjuvante, começam a evidenciar que elementos não tão racionais, e também entidades sociais, intervinham nos processos de tomada de decisão e consequentemente na estrutura das organizações. Essas interferências seriam tão fortes que poderiam gerar "vidas próprias, valores e símbolos até então creditados apenas às divindades" (QUINELLO, 2007, p. 17).

De acordo com Hall e Taylor (2003) duas questões devem ser fundamentais em toda análise institucional: como construir a relação entre instituição e comportamento?; e como explicar o processo pelo qual as instituições surgem ou se modificam. Para Quinello (2007, p. 61) a pergunta central da Teoria Institucional seria "por que as organizações (formais ou informais) tomam as formas que elas têm?".

Deste modo, e no intuito de busca destas respostas, autores ao longo do tempo exploraram questões fundamentais para o desenvolvimento da teoria institucional, conforme Quadro 2.

Quadro 2. Fases e Autores do Desenvolvimento da Teoria Institucional na Vertente Sociológica

\begin{tabular}{|c|c|l|c|}
\hline Autor & Década & \multicolumn{1}{|c|}{ Elementos } & Objetivo \\
\hline Berger e Luckmann & $60-70$ & Sociais & Realidade socialmente construída \\
\hline Meyer, Scott e Zuker & $70-80$ & $\begin{array}{l}\text { Padrões e práticas como valores } \\
\text { Sentimentos e significados }\end{array}$ & $\begin{array}{c}\text { Como a interação de padrões e } \\
\text { estruturas são legitimadas }\end{array}$ \\
\hline Powell e DiMaggio & $80-90$ & $\begin{array}{l}\text { Forças coercitivas, miméticas e } \\
\text { normativas }\end{array}$ & $\begin{array}{c}\text { Homogeneidade e similaridade entre } \\
\text { organizações }\end{array}$ \\
\hline
\end{tabular}

Fonte: Hall (1999 apud QUINELLO, 2007, p. 61).

Assim, na década de 60 a 70, segundo a visão de Carrieri e Leite-da-Silva (2006), Berger e Luckmann (1985) contribuem com a aproximação entre os aspectos culturais e organizacionais. Deste modo, Berger e Luckmann (1985 apud CARRIERI; LEITE-DA-SILVA, 2006, p. 58) entendem que "qualquer instituição tem um corpo de receitas de conhecimento transmitido que provê as regras apropriadas de conduta" aos seus atores. Nesta perspectiva "o mundo social e organizacional não é visto como um dado concreto, mas como uma criação das interações humanas, das quais resultam as inúmeras significações simbólicas manifestadas na cultura" (MACHADO-DA-SILVA; NOGUEIRA, 2000 apud CARRIERI; LEITE-DA-SILVA, 2006, p. 62), ou seja, traz à tona os elementos sociais, bem como a ideia da realidade socialmente construída.

$\mathrm{Na}$ década posterior, 70 a 80, enquanto Zucker (1977 apud ROSSONI, 2012) apenas menciona a legitimidade em sua discussão sobre persistência cultural, o artigo clássico de Meyer e Rowan (1977) compreende as implicações do uso da estrutura formal para propósitos simbólicos e ressaltam as limitações de explicações de cunho mais racional da estrutura. Os autores mantêm a ideia de Berger e Luckmann (1967), 
em que as regras institucionalizadas se dão por meio da construção social. Porém, Meyer e Rowan (1977) apontam a existência de limites nessa construção social, em que muitas vezes, a opinião pública, o prestígio social, a força da lei, e as obrigações normativas a influenciam. Os autores refutam o princípio defendido pelas teorias organizacionais que até então afirmavam que a estrutura formal era a maneira mais eficaz de controle e coordenação das complexas redes relacionais organizacionais. Neste momento, destaca-se que nem sempre a eficiência e desempenho são tidos como justificativa primordial na sobrevivência de uma organização (TOLBER; ZUCKER, 1999). Neste mesmo sentido, Scott et al. (2000 apud ROSSONI, 2012, p. 3) contribui para a teoria institucional ao apontar que as organizações "necessitam mais do que recursos técnicos e informação do ambiente, elas necessitam de aceitação e credibilidade".

Outro conceito importante na teoria institucional é a institucionalização. Tolbert e Zucker (1998, p. 194) relatam a partir da revisão de literatura, que "pouca atenção tem sido dada à conceitualização e à especificação dos processos de institucionalização" e ainda que a institucionalização aparece tanto como processo ou variável-atributo (institucionalizada ou não). Os autores complementam que os estágios da institucionalização variam em pré (estágio da habitualização), semi (estágio da objetificação) e completa institucionalização (estágio da sedimentação) - conforme apresentado na Figura 1, o que faz refletir a possibilidade de atendimento parcial (TOLBERT; ZUCKER, 1998).

Figura 1: Estágios à Institucionalização

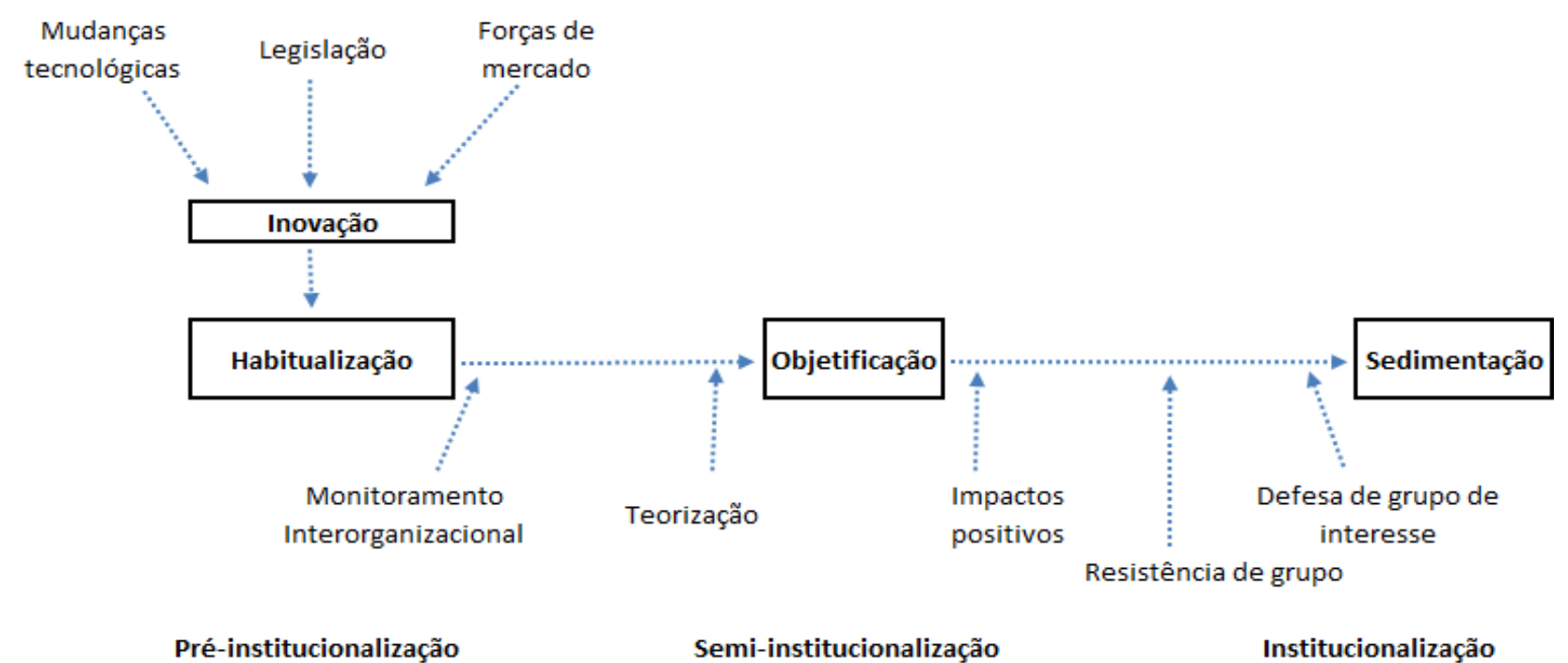

Fonte: Tolbert e Zucker (1998, p. 205).

Desta forma, habitualização é caracterizada como o estágio inicial, o qual busca desenvolver o comportamento padrão à solução de determinado problema e associar tal comportamento a estímulos particulares, considerado como uma atividade independente. De acordo com DiMaggio e Powell (1983 apud TOLBER; ZUCKER, 1998) como parte inerente da procura das organizações por soluções, e que podem ser desenvolvidas por outros, aqui estaria a justificativa de diversas organizações buscarem soluções similares ou até conjunta, caracterizando a imitação proposta pelos autores. Entende-se que a habitualização envolve a geração de novos arranjos estruturais em resposta a problemas ou conjuntos de problemas organizacionais específicos. 
O segundo estágio ou um status mais permanente e disseminado é denominado objetificação, o qual é entendido como a generalização do significado de uma ação (independente de quem desempenha), ou seja, na objetificação, que é, em parte, consequência do monitoramento que a organização faz dos concorrentes, envolve o desenvolvimento de certo grau de consenso social entre os decisores da organização a respeito do valor da estrutura, visando uma legitimidade cognitiva e normativa geral. Nesse estágio tem como característica bastante heterogeneidade dos adotantes.

Por último a sedimentação, a qual uma realidade que confronta o indivíduo como um fato externo e coercitivo, ou seja, processo por meio do qual as ações adquirem a qualidade de exterioridade e propagação, ou ainda, etapa que se apoia na continuidade histórica da estrutura e dada sua sobrevivência pelas várias gerações de membros da organização. Assim para que a sedimentação ocorra é necessário existir baixa resistência de grupos opositores, promoção e apoio cultural continuado dos grupos defensores e correlação positiva com os resultados esperados (TOLBERT; ZUCKER, 1998).

Assim, considera-se uma estrutura institucionalizada quando ela é tida pelos membros de um grupo social como eficaz e necessária, ou seja, um processo institucionalizado é definido como "uma tipificação de ações tornadas habituais por tipos específicos de atores" (BERGER; LUCKMANN, 1967 apud TOLBERT; ZUCKER, 1998, p. 202). Complementar, Berger e Luckmann (2001 apud BUSANELO, 2010) consideram a institucionalização como elemento central para a perpetuação dos grupos sociais. No mesmo sentido, tomase que as ações repetidas no decorrer do tempo, ganham um significado compartilhado intersubjetivamente entre os atores, o qual é definido como institucionalização e evolvem três momentos já mencionados: externalização [habitualização], objetivação e internalização [sedimentação] (BERGER; LUCKMANN, 1994 apud ROSSONI, 2006).

Vale ressaltar que as autoras, Tolbert e Zucker (1998) elencaram estes estágios como transposições de momentos, e na visão de Berger e Luckmann (1967, p. 129 apud MACHADO-DA-SILVA; GONÇALVES, 1998, pp. 222-223) "estes momentos não devem ser pensados como ocorrendo em uma sequência temporal" e a consideração de apenas um ou dois momentos torna a visão limitada frente ao fenômeno estudado, que é o processo de institucionalização da estrutura organizacional.

Por fim, na sequência do Quadro 2 que resume os principais marcos do desenvolvimento da Teoria Institucional, tem-se os anos de 1980 a 1990, onde DiMaggio e Powell (1991) discutem que a mudança estrutural aconteceria não por razões de eficiência ou pela necessidade de enfrentar a concorrência, mas em razão de outros processos que tornam as organizações mais semelhantes sem necessariamente fazê-las mais eficientes (DIMAGGIO; POWELL, 2005 apud CALDAS; FACHIN, 2007). DiMaggio e Powell (1983 apud LAMMERS; BARBOUR, 2006) alegaram que os líderes organizacionais, gestores e funcionários adotam e seguem regras institucionais que tornam as organizações mais semelhantes entre si, e a esse fenômeno denominaram isomorfismo. Percebe-se, assim, que as organizações buscam o isomorfismo por tentar se adequar as melhores práticas do mercado, ou então, por serem pressionadas por forças externas, e nem sempre as levam a maior eficiência.

Desta forma, esse tópico buscou esclarecer as principais fases e autores responsáveis pelo desenvolvimento da Teoria Institucional, destacando-se os estágios de institucionalização desenvolvidos por Tolbert e Zuker (1999) que são um dos pilares deste estudo. 


\section{PROCEDIMENTOS METODOLÓGICOS}

Metodologicamente, o estudo caracteriza-se como qualitativo, exploratório, descritivo, apresentando como estudo de caso o processo de institucionalização da Aintec/Uel. Assim, o Quadro 3 elenca os principais temas e os pontos de análise.

Quadro 3. Estrutura de Investigação Temática

\begin{tabular}{|c|l|}
\hline Tema em Perspectiva & \multicolumn{1}{|c|}{ O que investigar? } \\
\hline $\begin{array}{c}\text { As Relações entre } \\
\text { Comunicação e } \\
\text { Organização }\end{array}$ & $\begin{array}{l}\text { Fundamentações teóricas que permitam compreender as três relações } \\
\text { da comunicação com a organização, segundo Smith (1993). }\end{array}$ \\
\hline $\begin{array}{c}\text { O Processo de } \\
\text { Institucionalização } \\
\text { Organizacional }\end{array}$ & $\begin{array}{l}\text { Fundamentações teóricas que permitam a compreensão dos estágios } \\
\text { da institucionalização organizacional, proposta pela Teoria Institucional. }\end{array}$ \\
\hline $\begin{array}{c}\text { A Comunicação no } \\
\text { Processo de } \\
\text { Institucionalização }\end{array}$ & $\begin{array}{l}\text { Bases teóricas para a compreensão das contribuições e reflexões da } \\
\text { comunicação no processo de institucionalização. }\end{array}$ \\
\hline $\begin{array}{c}\text { O Caso Aintec/UEL } \\
\text { Busca apresentar, a partir do caso Aintec/UEL, evidências empíricas } \\
\text { sobre as relações da comunicação-organização e os estágios da } \\
\text { institucionalização organizacional. }\end{array}$ \\
\hline
\end{tabular}

Fonte: Elaborado pelos autores, 2012.

O estudo é qualitativo, pois busca compreender o fenômeno, a partir da perspectiva das pessoas envolvidas nele (GODOY, 1995) e possibilita estudar de forma adequada a natureza dos fenômenos sociais (RICHARDSON, 1989); e busca produção de sentidos do fenômeno estudado, além de interpretação da realidade social (RITCHIE; LEWIS, 2003).

Caracteriza-se também como um estudo exploratório por permitir ao investigador aumentar seu conhecimento a cerca de um determinado problema, em que ele aprofunda seu estudo nos limites de uma realidade específica (TRIVIÑOS, 2007). Neste caso, contribui ao propor uma aproximação entre a Teoria Institucional e as relações entre organização e comunicação, além de explorar como essas relações podem ser vistas nos processos de institucionalização. Ainda, tem-se que apesar das chamadas de atenção para o papel das instituições na comunicação organizacional, até o momento nenhuma teoria sistemática ou definição de instituição tem sido articulada na literatura de comunicação organizacional (LAMMERS; BARBOUR, 2006).

Já no que tange ao caráter descritivo, este estudo busca descrever as características do processo de institucionalização da Aintec/UEL a partir da Teoria Institucional e das relações da comunicação organizacional. Neste sentido, Triviños (1995) tem o entendimento de que o caráter descritivo é considerado como aquele que o pesquisador pretende conhecer uma comunidade, seus traços característicos, seus valores, dentre outras características. 
Também é um estudo de caso, pois possibilitou uma análise do objeto de estudo em maior profundidade (TRIVIÑOS, 2007). No caso deste trabalho, o estudo de caso na Aintec/UEL foi motivado pela busca em compreender como as relações entre organização e comunicação podem emergir no processo de institucionalização da agência. A escolha do caso foi feita de forma intencional (VERGARA, 2000), levandose em consideração o acesso às informações e a utilização de um caso que tivesse características vinculadas ao objeto de estudo, que é o processo de institucionalização.

O processo de coleta de dados e análise dos dados acorreu em dois momentos. Primeiro, para compreender o processo de institucionalização da Aintec/UEL, os autores recorreram ao trabalho de Zequini (2010), intitulado "O Processo de Estruturação de Núcleos de Inovação Tecnológica: o caso da Aintec". Especificamente, foram analisadas as transcrições das três entrevistas semi-estrutruradas realizadas pela autora, em que foram abordados pessoas-chave (1 diretor, 1 coordenador e 1 gerente) à implantação da Aintec (Agência de Inovação Tecnológica). Desta forma, obteve-se os dados referente ao processo de implementação da Agência, os quais foram analisados segundo as premissas das fases de institucionalização desenvolvidas por Tolbert e Zucker (1999).

Em um segundo momento, buscou-se entender mais especificamente como a comunicação permeou o processo de criação da Aintec. Assim, foi realizada uma entrevista em profundidade com o Diretor da Aintec, seguindo três objetivos: (a) esclarecer qual seu entendimento de comunicação; (b) após mostrar e explicar a Figura 2, a respeito do processo de institucionalização da Aintec, buscou-se compreender como a comunicação se constituiu em cada um dos estágios da institucionalização; (c) ao explicar brevemente as três relações entre organização e comunicação de Smith (1993), perguntou-se ao Diretor da Aintec qual relação ele acreditava ser a mais intensa em cada um dos estágios da institucionalização da Agência. Os dados da entrevista foram interpretados de acordo com as características fundamentais das três relações propostas por Smith (1993) entre organização-comunicação, tendo como fundo o processo de institucionalização da Agência. Os resultados estão apresentados na sequência.

\section{APRESENTAÇÃO E DISCUSSÃO DE RESULTADOS}

No intuito de atingir o objetivo geral apresenta-se o processo de institucionalização da Aintec/UEL como ilustração de evidências empíricas.

\section{O Processo de Institucionalização da Aintec/UEL}

A UEL é uma instituição pública de ensino superior, fundada em 28/1/1973 na cidade de Londrina, no estado do Paraná. Com o intuito de desenvolver ferramentas e meios para operacionalizar a transferência das invenções tecnológicas da universidade para o mercado e dessa forma, atender suas demandas e preservar as atividades básicas competentes às instituições de ensino superior, surgiu a Aintec/Uel, criada oficialmente em 17/4/2008 (ZEQUINI, 2010), assim como diversos núcleos de inovação tecnológica (NIT) que foram implantados em instituições de ciência e tecnologia (ICT), após o ano de 2004 devido a exigência da Lei Federal de Inovação (LIF) (TOLEDO, 2007 apud ZEQUINI, 2010). Neste sentido, a partir dos achados, é possível elencar as ações e cada estágio do processo de institucionalização (TOLBERT; ZUCKER, 1999) da Aintec/UEL, conforme Figura 2. 
Figura 2. Estágios do Processo de Institucionalização da Aintec/UEL

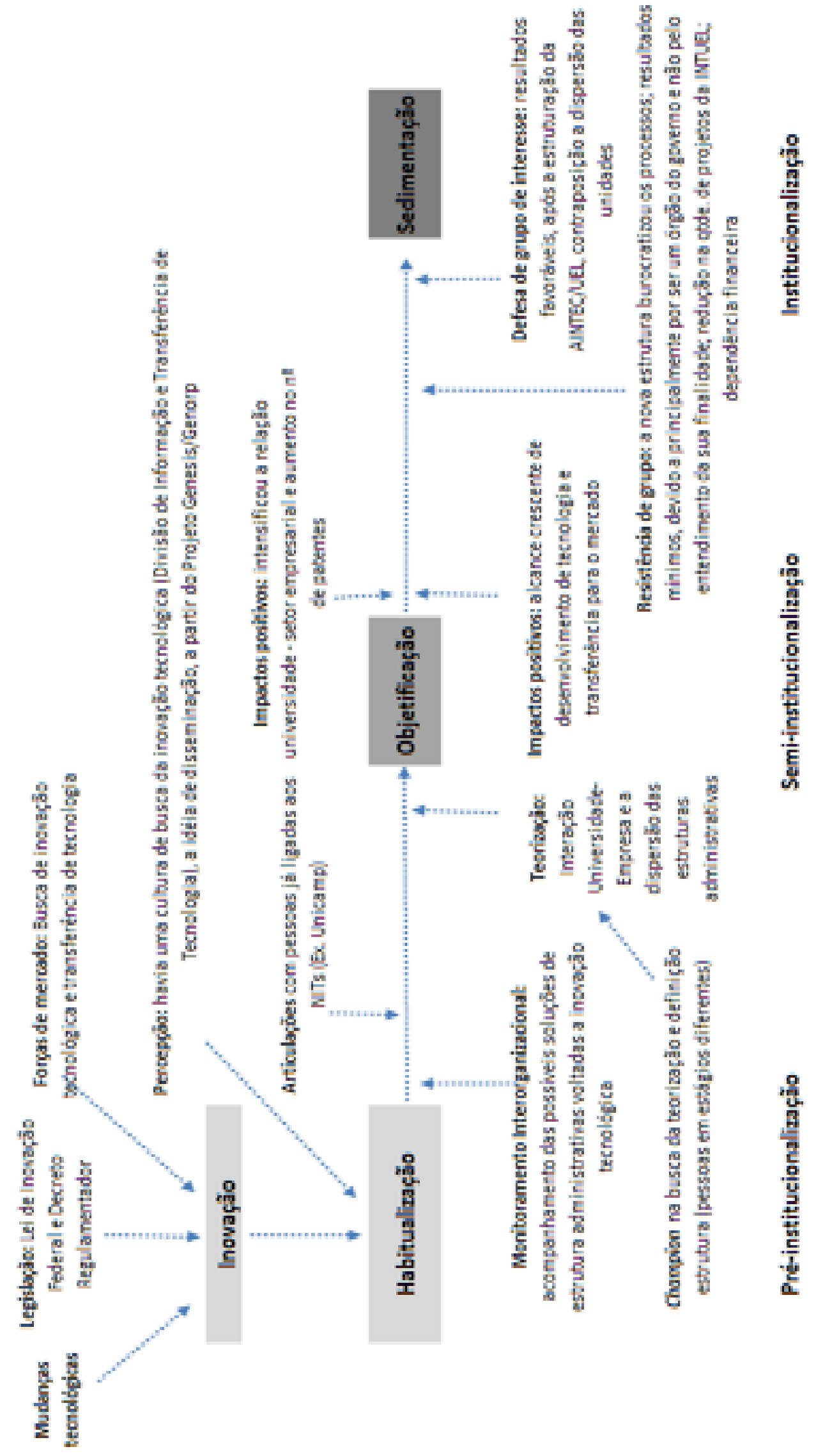

Fonte: Elaborado pelos autores, 2012. 
A partir de uma leitura mais ampla do processo de institucionalização da Aintec e a respeito dos estágios apresentados na Figura 2, pode-se concluir que a estrutura pensada (constituída) a partir da LIF está em processo de institucionalização, tendo em vista que a estrutura proposta passou a ser vista como a promotora dos resultados positivos, e que já pode ser evidenciada a necessidade de tal estrutura nos discursos dos integrantes da equipe, embora tais resultados devam ser consolidados ao longo do tempo. Percebe-se assim, através da fala dos entrevistados, a necessidade da existência da atual estrutura da Agência, critério importante para a validação social, visando a sedimentação da atual estrutura da Aintec.

Fica evidente nos achados que, embora a organização seja considerada como eficaz e necessária estágio de sedimentação (TOLBERT; ZUCKER, 1998), ainda faz necessário que tais ações e resultados se consolidem ao longo do tempo (ROSSONI, 2006). Vale ressaltar que as autoras, Tolbert e Zucker (1998) elencam estes estágios como transposições de momentos, e na visão de Berger e Luckmann (1967, p. 129 apud MACHADO-DA-SILVA; GONÇALVES, 1998, p. 222-223) "estes momentos não devem ser pensados como ocorrendo em uma sequência temporal" e a consideração de apenas um ou dois momentos torna a visão limitada frente ao fenômeno estudado, que é o processo de institucionalização da estrutura organizacional.

Diante da relação organização-comunicação, foi questionado ao Diretor da Aintec qual seu entendimento sobre comunicação, em que o mesmo colocou que:

são as relações que você faz, tem o pessoal interno, para transmitir as informações, processos das ações, o que se pretende que cada um faça, e encontrar instrumentos pra isso, e ter sempre que possível um feedback. A mesma coisa com o pessoal externo, para falar como a Agencia opera, qual a função, quais são suas unidades, como dentro das suas ações de operação se interage com a Agência, todo processo de troca de informações da organização com as pessoas que estão dentro e com as pessoas de fora, tanto universidade, pessoal acadêmico, como fora da universidade. Primeiro identifica quais são agentes que tem que comunicar, quais os processos, e depois operacionaliza.

Assim, nota-se que o entrevistado possui visão mecanicista sobre a comunicação, em que a comunicação é vista como contida na estrutura organizacional (SMITH, 1993) sendo apenas uma de suas variáveis (CASALI, 2004).

Vale também destacar no processo de institucionalização a figura do champion, bem como a articulação com outras entidades, visando o monitoramento das possíveis soluções buscadas por outras instituições, para problemas comuns, que são apresentadas de forma discursiva e na disseminação da informação. Embora a autora percussora das relações da comunicação-organização Smith (1993) não fale que pode haver duas ou mais relações ao mesmo tempo, acreditava-se que nesta fase de habitualização, a relação entre organização e comunicação seria tanto de contenção, como de produção, haja vista a crença em que ao mesmo tempo em que se faz necessário o processo informacional, com a simples transferência de informações da figura do champion aos demais, ocorre também a construção de sentidos. 
Porém, verificou-se na entrevista realizada com o Diretor da Aintec que a relação foi puramente informacional, uma vez que foi ele mesmo que levou a ideia de estruturação da Agência para a alta administração da universidade, através dos requisitos da legislação. $O$ entrevistado apontou falta de conhecimento dentro da universidade, e que a maior parte da vinculação foi mesmo com a Administração, diretamente com o gabinete do reitor, com a Proplan e com o Pró-reitor de Pesquisa. Ele também coloca que houve conversas informais com professores, mas com a finalidade de informá-los sobre a legislação. Deste modo, percebe-se que o processo de estruturação da Aintec não foi um processo organizante, com construção de diversos sistemas de significados (MUMBY, 2000 apud CASALI, 2004), características essenciais das relações de produção e equivalência. Portanto, neste caso, confirma-se a comunicação vista como um processo linear, definida pelas necessidades organizacionais de ordem prática (CASALI, 2009). O que pode inferir a não sedimentação da Aintec.

Ainda na fase de habitualização, o Diretor da Aintec afirmou que a escolha da estrutura foi resultado das reuniões com a Administração da universidade, parte mais formal do processo de criação da Aintec. Nessas reuniões, que não eram periódicas, ele apresentava a fase em que se encontrava o projeto de estruturação da Agência, além de apresentar os resultados dos materiais coletados dos outros NITs, já que toda essa articulação foi ele quem conduziu. Assim, de acordo com sua fala:

eu coletava o material (dos outros NITs) e nessas reuniões eu levava pro pessoal. As estruturas que nós temos são essas aqui, e em função do que nós temos, poderia, então, talvez, fazer uma estrutura desse tipo, que tá dentro do que parece ser mais dinâmico do que outros lugares. A parte de escolha da estrutura foi resultado dessa reunião com a Administração. Em relação aos professores era mais pra informar, [...] eles não davam ideias, não, não, muito pouco.

Já na fase de objetificação, em que são monitorados os aspectos positivos e negativos da nova estrutura, o Diretor da Aintec afirmou que "tivemos reuniões internas às vezes de quinze em quinze dias envolvendo a equipe inteira, que envolve todos os funcionários, até mesmo os estagiários; agora as reuniões setoriais ocorrem direto". Ele esclarece que as reuniões em que todos os funcionários participam são basicamente para verificar se o planejamento feito no início do ano está sendo desenvolvido, quais são as dificuldades, se há necessidade de fazer um realinhamento, mas o foco mesmo está nos resultados da Agência. Por outro lado, as setoriais são mais para resolver os problemas, para operacionalizar.

Porém, foi possível verificar que as reuniões gerais foram planejadas para ocorrer quinzenalmente, mas que nos últimos oito meses, por exemplo, teria acontecido por volta de quatro reuniões. Além disso, destacou-se que estas possuem um caráter informativo, em que cada um expõe as atividades que tem realizado.

No último momento da entrevista com o Diretor da Aintec, explicou-se brevemente as três relações entre organização e comunicação propostas por Smith (1993), e pediu ao entrevistado que apontasse qual ou quais dessas relações ele via como mais intensidade em cada uma das fases de institucionalização da Aintec. 
Após a explicação ele apontou a equivalência como "um processo quase natural, precisando de muita maturidade, você tem que passar pela fase estruturante, estruturada, melhor dizendo". Assim, ele disse que, no momento, a comunicação poderia ser vista na Agência pela metáfora do contêiner e da produção. $\mathrm{E}$ retomando o início do processo de institucionalização, na fase de habitualização, ele afirmou:

No começo foi informação pura e simples, isso em relação à universidade. A minha relação com as informações exteriores ai não era porque tinha que pegar tudo isso e analisar, ver se adaptava ou não. Mas entre eu e a estrutura da Universidade era informacional mesmo, o resto era trabalho operacional. As reuniões com Administração era informacional. Até a escolha da estrutura foi informacional.

$\mathrm{Na}$ fase de objetificação, em relação à parte da avaliação dos impactos positivos e/ou negativos, o mesmo também acredita que a relação foi a de contêiner, entre eles e a Administração. E entre os funcionários da Aintec, afirmou que "[...] (tempo pra pensar), na verdade a gente construiu essa avaliação, foi uma construção junta, pela questão da novidade. É uma construção da avaliação. Ao mesmo tempo em que fica sabendo da informação, constrói o valor sobre ela". Quando questionado sobre a comunicação externa, o Diretor da Aintec respondeu que

tem o site, a gente está sempre fazendo folder, a gente faz evento, são vários instrumentos. E com as empresas nós temos eventos que a gente comunica, [...] participa de rodada de negócios, então usa vários desses instrumentos para mostrar que a gente existe, levo folder, para mostrar qual a função da Agência.

Percebe-se que, apesar da fala do entrevistado sobre a questão da construção da avaliação que parece denotar um aspecto mais relacional, o processo de monitoramento dos resultados da Agência é informacional, tanto para o público interno quanto externo, pautado em "uma visão mecanicista e linear da comunicação, a qual pode ser medida e avaliada" (MARCHIORI, 2009, p. 6), ou seja, a comunicação é vista como um recurso, que liga os elementos funcionais e estruturais da organização.

Assim, nota-se que nas fases de institucionalização da Aintec emergiu de forma intensa a relação entre a organização e comunicação vista como um contêiner, predominando a ideia de comunicação como simples transferência de informações. Fato talvez tão marcante pelas ações de estruturação da Agência ficar a cargo quase que exclusivamente do Diretor da Aintec, que foi o responsável por levar a ideia até a alta administração da Universidade, e pelo mesmo centralizar todo o projeto de condução de criação da Agência.

Quanto às relações de produção e equivalência, não foi possível captá-las nos estágios de institucionalização, uma vez que não se destacou a importância dos indivíduos no processo de organizing, ou ainda, pelo fato da Aintec não estar institucionalizada, as metáforas de produção e equivalência são de menor expressão Deste modo, a interpretação e releitura dos resultados sugerem que não se constatou, através das entrevistas, engajamento e construção de significados por parte dos membros da organização no processo de institucionalização da Agência. 


\section{CONSIDERAÇÕES}

O trabalho foi desenvolvido buscando compreender quais relações entre comunicação-organização podem emergir nos estágios da institucionalização. Com base em Smith (1993), foi possível analisar a existência de três relações principais entre comunicação e organização. A primeira, a do contêiner (ou contenção), a comunicação desempenha funções operacionais, de manutenção, de relações humanas; assim, a comunicação é vista "como uma ferramenta para atingir os objetivos organizacionais" (PUTMAN; PHILLIPS; CHAPMAN, 2004, p. 82), ou seja, a relação pode ser equiparada ao processo de monitoramento organizacional, entre os estágios da habitualização e objetificação.

Os outros dois tipos de relações propostos por Smith (1993) - produção e equivalência - estão inseridos na ideia de "comunicação como organização". Porém, a relação de equivalência postula uma mudança radical no relacionamento comunicação/organização (CASALI, 2009). Neste contexto, essa abordagem trata comunicação e organização como processos isomórficos (PUTNAM; PHILLIPS; CHAPMAN, 2004), remetendo ao pensamento de que "a comunicação é organização, assim como organização é comunicação" (CASALI, 2009, p. 112).

Para satisfazer o objetivo do trabalho também foi necessário revisar a evolução da Teoria Institucional através das contribuições dos principais autores. Assim, nos remetem aos estágios à institucionalização (TOLBERT; ZUCKER, 1998), os quais consistem em: habitualização, objetificação e sedimentação; contribuindo para a proposta de construção de uma análise macro a partir dos olhares da comunicação.

$\mathrm{Na}$ sequência, buscou a apresentação e discussão dos resultados a partir do processo de institucionalização da Aintec/Uel, em que foi possível elencar as ações em cada estágio do processo de institucionalização da Aintec/UEL, além da possibilidade em identificar como essas ações puderam contribuir para que a atual estrutura estivesse entre os estágios de objetificação (semi-institucionalização) e a sedimentação (institucionalização).

Nota-se ainda, que a relação da contenção a qual procura a transmitir a comunicação é a mais frequente do ponto de vista da visibilidade prática (disseminação do problema organizacional, figura do champion no convencimento das ações, disseminação dos impactos positivos, busca de solução para os problemas).

Quanto às relações de produção e equivalência, não foi possível captá-las nos estágios de institucionalização da Aintec, uma vez que não houve destaque para a importância dos indivíduos no processo de organizing, talvez por todo o processo de estruturação da Agência ter ficado quase que exclusivamente na responsabilidade de uma única pessoa.

Como limitação do presente estudo, tem-se o caráter ainda exploratório da abordagem, bem como a quantidade de organizações analisadas. Neste contexto, como sugestões para pesquisas futuras tem-se a ampliação dos olhares da comunicação nos processos de institucionalização organizacional, bem como da quantidade de organizações a serem analisadas. 


\section{REFERÊNCIAS}

BURRELL, G.; MORGAN, G. Sociological Paradigms and Organizational Analysis. Hant: Ashgate, 2006.

CALDAS, M. P. O Nexo Comunicação-Organização: um prelúdio às múltiplas avenidas de cooperação e de mútuo aprendizado entre comunicação organizacional e estudos organizacionais (prefácio ao livro). In: MARCHIORI, M. R. (Org.). Comunicação e Organização: reflexões, processos e práticas. São Caetano do Sul/SP: Difusão Editora, 2010.

CALDAS, M. P.; FACHIN, R. Paradigma Funcionalista: desenvolvimento de teorias nos anos de 1980 e 1990. In: CALDAS, M. P; BERTERO, C. O. (Orgs.). Teoria das Organizações. São Paulo: Atlas, 2007.

CARRIERI, A. P.; LEITE-DA-SILVA, A. R. Cultura Organizacional versus Cultura nas Organizações: conceitos contraditórios entre o controle e a compreensão. In: MARCHIORI, M.R. (Org.). Faces da Cultura e da Comunicação Organizacional. São Paulo: Difusão, 2006.

CASALI, A. M. Paradigmas em Comunicação Organizacional. Congreso Latinoamericano de Investigadores de la Comunicación (ALAIC). GT Comunicação Organizacional y Relaciones Públicas. La Plata / Argentina, 2004.

CASALI, A. M. Um Modelo do Processo de Comunicação Organizacional na Perspectiva da "Escola de Montreal". In: KUNSCH, M. M. K. (Org.). Comunicação Organizacional: histórico, fundamentos e processos. São Paulo: Saraiva, 2009, p. 107-134.

CHANLAT, J. F. O Indivíduo nas Organizações: dimensões esquecidas. v.1. São Paulo: Atlas, 1996.

GODOY, A. S. Pesquisa Qualitativa: tipos fundamentais. Revista de Administração de Empresas, v. 35, n. 3, p. 20-9, mai./jun. 1995.

HALL, P. A.; TAYLOR, R. C. R. As Três Versões do Neo-institucionalismo. Lua Nova, n. 58, p. 193-223, 2003.KUNSCH, M. M. K. Percursos paradigmáticos e avanços epistemológicos nos estudos da comunicação organizacional. In: KUNSCH, M. M. K. (Org.). Comunicação Organizacional: histórico, fundamentos e processos. São Paulo: Saraiva, 2009, p. 63-89.

LAMMERS, J. C.; BARBOUR, J. B. An Institutional Theory of Organizational Communication. Communication Theory, v. 16, n. 3, p. 356-377, 2006.

MACHADO-DA-SILVA, C. L.; GONÇALVES, S. A. Nota Técnica: a teoria institucional. In: CLEGG, S. et al. (Org.). Handbook de Estudos Organizacionais. v.1. São Paulo: Atlas, 1998.

MARCHIORI, M. R. ¿Por qué hoy en día precisamos cultura organizacional? Una perspectiva de comunicación única en el área posmoderna. Diálogos de la Comunicación, n. 78, Enero-Julio 2009.

MARCHIORI, M. R. Cultura e Comunicação Organizacional: uma perspectiva abrangente e inovadora na proposta de inter-relacionamento organizacional. In: MARCHIORI, M. R. (Org.). Faces da Cultura e da Comunicação Organizacional. 2. ed. v. 1. São Caetano do Sul: Difusão, 2008.

MARCHIORI, M. R. Introdução. In: MARCHIORI, M. R. (Org.). Comunicação e Organização: reflexões, processos e práticas. São Caetano do Sul/SP: Difusão Editora, 2010.

MARCHIORI, M. R.; OLIVEIRA, I. L. Perspectives, challenges and future directions for organizational communication research in Brazil. Management Communication Quarterly, v. 22, n. 4, p. 671-676, may 2009.

MARCHIORI, M. R. ¿Por qué hoy en día precisamos cultura organizacional? Una perspectiva de comunicación única en el área posmoderna. Diálogos de la Comunicación, n. 78, Enero-Julio 2009

MATTOS, M. A. Interfaces do Saber Comunicacional e da Comunicação Organizacional com Outras Áreas de Conhecimento. In: OLIVEIRA, I. L.; SOARES, A. T. N. (Eds.), Interfaces e Tendências da Comunicação no Contexto das Organizações, p. 17-37. São Caetano do Sul, SP: Difusão, 2008.

MEYER, J.W.; ROWAN, B. Institutionalized Organizations: Formal Structure as Myth and Ceremony. The American Journal of Sociology, v. 83, n. 2, p. 340-363, sep. 1977.

PUTNAM, L.; PHILLIPS, N.; CHAPMAN, P. Metáforas da Comunicação e da Organização. In: CLEGG, S. et al. (Org.). Handbook de Estudos Organizacionais. v.3. São Paulo: Atlas, 2004.

QUINELLO, R. A Teoria Institucional Aplicada à Administração: entenda como o mundo invisível impacta na gestão dos negócios. São Paulo: Novatec Editora, 2007.

REIS, M. C.; COSTA, D. A Zona de Interseção entre o Campo da Comunicação e o dos Estudos Organizacionais. In: XV Encontro da Associação Nacional dos Programas de Pós-Graduação em Comunicação (COMPÓS), Bauru/SP, 2006.

RICHARDSON, R. J. Pesquisa social: métodos e técnicas. São Paulo: Atlas, 1989.

RITCHIE, J.; LEWIS, J. Qualitative Research Practice: a guide for social science students and researchers. Sage Publications, London, 2003.

ROSSONI, L. A Dinâmica de Relações no Campo da Pesquisa em Organizações e Estratégia no Brasil: uma análise institucional. 2006. 296 f. Dissertação (Mestrado em Administração) - Universidade Federal do Paraná (UFPR), Curitiba/PR, 2006. 
ROSSONI, L. O Que é Legitimidade Organizacional. In: VII Encontro de Estudos Organizacionais (EnEO), Curitiba/PR, 2012.

SMITH, R. C. Images of organizational communication: Root-metaphors of the organization-communication relation. Paper presented at the annual meeting of the International Communication Association, Washington, DC. 1993.

TAYLOR. J. R.; DELCAMBRE, P. La Communication Organisationnelle: histoire, enjeux et fondements. In: GROSJEAN, S.; BONNEVILLE, L. (Eds.). Communication Organisationnelle: approches, processus et enjeux, Montréal : Chenelière Éducation, 2011.

TAYLOR, J.; VAN EVERY, E. The emergent organization. New Jersey: Erlbaum, 2000.

TOLBERT, P. S.; ZUCKER, L. G. A Institucionalização da Teoria Institucional. In: CLEGG, S. et al. (Org.). Handbook de Estudos Organizacionais. v.1. São Paulo: Atlas, 1998.

TRIVIÑOS, A. N. S. Introdução à Pesquisa em Ciências Sociais: a pesquisa qualitativa em educação: o positivismo, a fenomenologia, o marxismo. São Paulo: Atlas, 2007.

VERGARA, S. C. Projetos e Relatórios de Pesquisa em Administração. 3.ed. São Paulo: Atlas, 2000.

VIEIRA, M. M. F.; CARVALHO, C. A. Organizações, Instituições e Poder no Brasil. Rio de Janeiro: FGV, 2003.

VIEIRA, S. F. A. Dinâmica de Atuação dos Stakeholders em Atividades Estratégicas: a experiência da Secretaria de Estado do Turismo do Paraná. 2010. 188 f. Tese (Doutorado em Administração) - Universidade Nove de Julho UNINOVE, São Paulo, 2010.

YIN, R. K. Estudo de Caso: planejamento e métodos. 2.ed. Porto Alegre: Editora Bookman, 2001.

ZEQUINI, R. T. O Processo de Estruturação de Núcleos de Inovação Tecnológica: o caso da Aintec. 2010.198 f. Monografia. (Graduação em Administração) - Universidade Estadual de Londrina - UEL, Londrina, 2010. 